\title{
Kerry L. Yurewicz \\ A growth/mortality trade-off in larval salamanders and the coexistence of intraguild predators and prey
}

Received: 27 January 2003 / Accepted: 27 August 2003 / Published online: 26 September 2003

C) Springer-Verlag 2003

\begin{abstract}
Behavioral and morphological traits often influence a key trade-off between resource acquisition and vulnerability to predation, and understanding trait differences between species can provide critical insight into their interactions with other species and their distributions. Such an approach should enhance our understanding of the criteria for coexistence between species that can interact through both competition and predation (i.e. intraguild predators and prey). I conducted a common garden experiment that revealed strong differences between three guild members (larval salamanders Ambystoma laterale, A. maculatum, and A. tigrinum) in behavior, morphology, and growth in the presence and absence of a shared top predator (the larval dragonfly Anax longipes). All three species also reduced their activity and modified their tail fin depth, tail muscle length, and body length in response to non-lethal Anax. Species that act as intraguild predators were more active and could grow faster than their intraguild prey species, but they also suffered higher mortality in laboratory predation trials with Anax. I also used survey data from natural communities to compare the distribution of Ambystoma species between ponds differing in abiotic characteristics and predatory invertebrate assemblages. An intraguild prey species (A. maculatum) was found more reliably, occurred at higher densities, and was more likely to persist late into the larval period in ponds with more diverse invertebrate predator assemblages. Taken together, these results indicate that top predators such as Anax may
\end{abstract}

\section{K. L. Yurewicz $(\bowtie)$}

Department of Biology, University of Michigan,

Ann Arbor, MI 48109, USA

e-mail: kyurewic@nd.edu

Tel.: +1-574-6310949

Fax: +1-574-6317413

Present address:

K. L. Yurewicz

Department of Biological Sciences, University of Notre Dame,

Notre Dame, IN 46556, USA play an important role in influencing intraguild interactions among Ambystoma and ultimately their local distribution patterns.

Keywords Ambystoma · Behavior · Morphology · Phenotypic plasticity $\cdot$ Predation risk

\section{Introduction}

In many communities, members of one species (the intraguild predator) can both prey upon and compete with members of a second species (the intraguild prey) for shared resources (Fig. 1a). A key question in these systems is how intraguild prey persist in the face of both competitive and predatory pressure from their intraguild predators. Theory indicates that coexistence between intraguild predators and prey is possible when the latter species has a competitive advantage. However, intraguild predation (IGP) has the potential to create unstable population dynamics that can enhance extinction probabilities (Polis et al. 1989; Holt and Polis 1997), and Holt and Polis (1997) concluded that species coexistence in situations with strong, persistent IGP "raises a puzzle". The ubiquity of IGP in nature (Polis et al. 1989) and empirical work demonstrating that intraguild prey often persist in spite of strong, negative impacts of their intraguild predators (Diehl 1993) indicates that this puzzle has not been fully solved.

Part of the difficulty in explaining coexistence between intraguild predators and intraguild prey may stem from the fact that theoretical and empirical work on IGP has largely been restricted to the three-species module (Fig. 1a), ignoring other members of the communities in which these species are embedded. The observation of strong densitymediated indirect effects on diversity [e.g., keystone predator effects: Power et al. (1996)] and the pervasiveness of trait-mediated indirect effects within food webs (Werner and Peacor 2003) illustrate that coexistence between particular species may be difficult to explain when taken out of the context of the larger community. In 
(A)

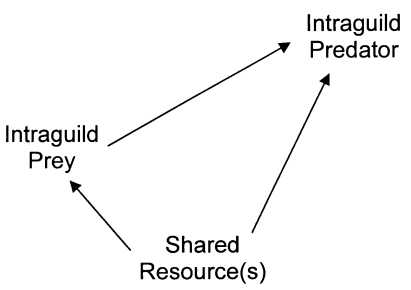

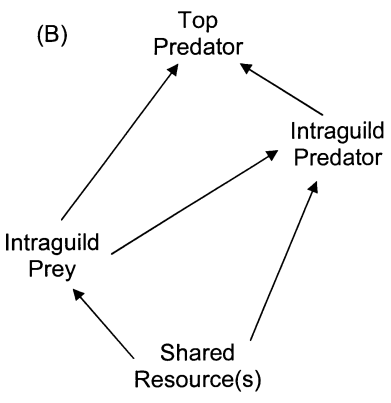

Fig. 1 Diagrams of food webs with IGP in the absence (A) and presence (B) of a top predator. Arrows point from resources to their consumers

terms of IGP, limiting the focus to the relative competitive abilities of intraguild predators and prey for shared resources ignores the fact that traits affecting foraging gain are also likely to affect vulnerability to other predators. For example, animals with higher activity levels often have an advantage in resource acquisition but are more likely to be detected and captured by top predators (Werner and Anholt 1993). The trade-off between competitive ability and predation risk is known to affect species distributions in a wide variety of taxa (Wellborn et al. 1996). These observations suggest that expanding theory and experiments on intraguild predators and prey to include top predators is likely to enhance our understanding of the criteria for coexistence between such species (Fig. 1b).

A recent study by Wissinger et al. (1999) makes a compelling case for the importance of top predators in influencing coexistence between intraguild predators and prey. In this study, a caddisfly intraguild predator (Asynarchus) was more active and aggressive than its intraguild prey (the caddisfly Limnephilus), giving it a competitive advantage. However, the traits of the intraguild predator were also associated with higher mortality in the presence of a top salamander predator. By preferentially consuming Asynarchus, the salamander predator facilitated the persistence of Limnephilus with its competitive superior. Understanding the effects of a top predator on intraguild predators and prey enabled the investigators to explain shifts in the relative abundance of the two caddisfly species across the range of wetlands where they were observed (Wissinger et al. 1999). The key to their study, and to future studies on IGP, lies in focusing on the traits of intraguild predators and prey and their consequences to interactions with other species to elucidate the mechanisms underlying their performance in different contexts.

In this study, I conducted experiments and surveys of natural populations to relate trait differences between intraguild predators and prey to their performance and their distributions along a habitat gradient. The study system consisted of three species of salamander larvae (intraguild predators and prey) and one larval dragonfly species (top predator). Larval salamanders typify many organisms that interact through IGP in that they are generalist predators for whom size structure strongly influences the probability of competitive versus predatory interactions (Polis et al. 1989). Thus, insight gained into IGP from this system should be relevant to a variety of taxa. The species used in this study (Ambystoma tigrinum, A. laterale, and A. maculatum) co-occur in a variety of ponds that dry periodically in southeastern Michigan (Skelly et al. 1999). All three species overlap considerably in resource use (Brophy 1980; Nyman 1991) and can compete if resources are limiting (Wilbur 1972). Differences in hatching time and growth rates establish interspecific size differences that often make it possible for A. tigrinum to consume both of its congeners and for $A$. laterale to consume A. maculatum (Wilbur 1972; Nyman 1991; Yurewicz 2002). Thus, both competition and predation can occur between each pair of species.

I chose a larval aeshnid dragonfly (Anax longipes) as the top predator for this study because larval aeshnids are voracious predators on larval amphibians (Caldwell et al. 1980; Van Buskirk 1988) and co-occur with Ambystoma in natural communities in Michigan (personal observation). Further, many amphibians can detect the presence of chemical cues from aeshnids (McCollum and Leimberger 1997; Relyea 2001a), making it possible to manipulate the perception of predation risk by exposing individuals to non-lethal (caged) predators. Thus, the effects of Anax on Ambystoma traits and performance can be examined both in the presence and absence of effects on mortality.

I employed a three-part approach to studying traits and IGP in this system. First, I conducted a common garden experiment to quantify the behavior, morphology, growth rates, and survival of the three Ambystoma species when they were raised separately in the presence and absence of non-lethal (caged) Anax. This experiment was designed to reveal whether key traits potentially related to resource acquisition and vulnerability to the top predator differed between intraguild predator and prey species. The treatment with non-lethal Anax was included to determine whether Ambystoma species respond to perceived predation risk in ways that would allow the top predator to exert trait-mediated effects on intraguild interactions. Second, I used laboratory predation trials to compare survival between pairs of Ambystoma species in the presence of lethal (uncaged) Anax. The purpose of this experiment was to test the prediction that interspecific trait differences quantified in the common garden experiment would influence relative vulnerability to a top predator (e.g., more active species should suffer higher mortality). This, in turn, reveals the potential for the top predator to influence coexistence between the salamander guild members by altering their relative abundances. Finally, I sampled natural communities in southeastern Michigan to compare the occurrence and densities of Ambystoma species between ponds differing in abiotic characteristics (such as pond permanence) and predatory invertebrate assemblages. The purpose of this survey was to evaluate whether the distribution patterns of the ambystomatid intraguild predators and prey reflect a trade-off between resource acquisition and the risk of mortality from other predators in their communities. Taken together, the 
experimental and survey results suggest that the presence of top predators and the trait differences between Ambystoma species have important implications for intraguild interactions, species coexistence, and natural distributions.

\section{Materials and methods}

For experiments, I collected Ambystoma as eggs from ponds in Livingston County, Mich., and placed them into a series of singlespecies wading pools covered with $60 \%$ shade cloth. After hatching, larvae were fed a mixture of cladocerans and copepods collected from nearby ponds until their use in experiments. Anax larvae were collected from experimental ponds on the University of Michigan's E.S. George Reserve in southeastern Michigan. They were housed individually in small plastic containers in the lab for at least 1 day prior to their use in experiments.

\section{Common garden experiment}

In 1997, I raised larvae of $A$. laterale, $A$. maculatum and $A$. tigrinum in outdoor wading pools in the presence and absence of non-lethal (caged) predatory dragonfly larvae (Anax longipes). Each pool contained ten individuals of one of the Ambystoma species as well as one caged predator or an empty cage. For each species, there were four replicates of each predator treatment divided equally among two spatial blocks. Experimental units were 75-1 or 100-1 wading pools (bottom area $\approx 0.34 \mathrm{~m}^{2}$ or $0.52 \mathrm{~m}^{2}$ ) that were filled with well water and contained 75 or $100 \mathrm{~g}$ dried leaves (primarily Quercus spp.) to provide structure to the environment (Block I and II, respectively). All pools were covered with lids made from $60 \%$ shade cloth to prevent unwanted amphibians and invertebrates from colonizing the experiment. Several days before salamander larvae were introduced, I added to each pool the same volume of a collection of zooplankton (small cladocerans and copepods) taken from a nearby pond. Throughout the experiment, I replenished this food source ad libitum whenever zooplankton was not easily visible in many pools by again adding to each pool the same amount (by volume) of a well-mixed sample of recently collected cladocerans and copepods.

In the center of each pool was one predator cage $($ a $10 \times 11 \mathrm{~cm}$ piece of black plastic drain pipe with $2 \mathrm{~mm}$ fiberglass screening over each end and a small piece of polystyrene for flotation), which was either empty or contained one Anax. I fed each predator approximately $300 \mathrm{mg}$ of prey (i.e., salamander larvae) every other day during the experiment. Predators were always fed the species of Ambystoma in that pool so that salamanders were exposed to cues produced by predators consuming conspecifics. Cages in nopredator pools were also picked up and dropped back into the water at each feeding date to control for disturbance.

I quantified activity levels of salamander larvae by removing the lids from all pools, waiting approximately 15-20 min, and then walking or crawling slowly along the sides of the pools and scoring how many individuals were swimming and how many animals were seen at the moment of observation in each pool. Each pool was observed at least 13 times during a 2 -week period, and I used the average proportion of individuals seen swimming across all observations as an estimate of activity level for each pool.

Larvae of all three salamander species spent 32 days in the experiment. However, because of differences in hatching time between the three species, not all pools could be set up at the same time. A. tigrinum and A. laterale larvae were added to their pools on 26 May. At the start of the experiment, A. tigrinum individuals weighed $60 \pm 3 \mathrm{mg}($ mean $\pm 1 \mathrm{SE})$, and $A$. laterale larvae weighed 41 $\pm 2 \mathrm{mg}$. A. maculatum larvae were added to their pools on 15 June; they weighed $72 \pm 2 \mathrm{mg}$ at that time. At the end of the experiment, I recaptured all surviving individuals and preserved them in $10 \%$ formalin for morphological analysis.
To examine morphology, I used the BioScan Optimas computer image analysis program to trace video images of the preserved salamander larvae. For each specimen, I measured maximum body depth, maximum tail muscle depth and maximum tail fin depth from a lateral view. For these measurements, I placed a glass slide underneath each larva's tail so that it would lie flat and even with the rest of the body. I then positioned each larva on its back to measure head length, maximum head width, body length, maximum body width, tail muscle length, and maximum tail muscle width. Each larva was also weighed at this time. Measurements from individuals that were undergoing metamorphosis or had extensive tail damage were excluded from the morphological analysis.

Survival data had heteroscedastic error variances and were analyzed nonparametrically. I used Mann-Whitney $U$ tests to compare survival between blocks and predator treatments and Kruskal-Wallis tests to evaluate differences between species and between species-by-predator groups. I analyzed growth with a threeway analysis of covariance (ANCOVA) that tested the effects of block, species, and predator treatment as well as all of their interactions on the log-transformed final mass of individuals corrected for log-transformed initial mass. When the ANCOVA revealed significant effects, I used Fisher's LSD test to make multiple comparisons.

Activity was analyzed in a three-way analysis of variance (ANOVA) that included the main effects of block, salamander species, and predator treatment, as well as the interactions between these factors. Activity data were log-transformed to meet the assumptions of normality and homoscedasticity. One pool was identified as an outlier using Dixon's test (Dixon 1950, 1951: $\left.r_{10}=0.80, P<0.05\right)$ and was excluded from this analysis. When the ANOVA revealed significant effects, I used Fisher's LSD test for mean comparisons.

To compare the morphology of individuals between species and treatments, I first log-transformed mass and all morphological measurements to correct for non-linearities. Next, I regressed each morphological variable against mass to correct for differences in size between individuals and calculated the mean residual values by pool. These mean residuals, representing size-independent morphology, were entered into a multivariate analysis of variance (MANOVA) that included the effects of salamander species, predator treatment, and the species-by-treatment interaction. The main and interactive effects of block were not included after initial analyses revealed that they did not have significant effects. When the MANOVA revealed significant multivariate effects, I conducted univariate tests and compared means with Fisher's LSD test. I used one-sample Kolmogorov-Smirnov tests and Levene's tests, respectively, to evaluate normality and homoscedasticity of the data and found no serious violations.

\section{Predation trials}

In 2000 , I conducted laboratory predation trials in $8-1$ plastic bins $\left(37 \times 24 \times 16 \mathrm{~cm}\right.$, bottom area $\left.\approx 0.09 \mathrm{~m}^{2}\right)$ filled with aged well water. Each bin contained one Anax and ten individuals of each of two Ambystoma species. This allowed me to assess differences in vulnerability to the top predator between each intraguild predator and prey combination. There were four replicates of each pairwise combination of salamander species. A cluster of four strands of plastic rope (strand length $=1 \mathrm{~m}$ ) in each bin provided structural complexity. Bins were arranged in a completely randomized design along shelves in the laboratory under fluorescent lighting that operated on a 14:10 light:dark cycle.

Each Anax was placed in a cage (a $120 \mathrm{ml}$ plastic cup with a piece of polystyrene inside for flotation and a piece of $2 \mathrm{~mm}$ fiberglass screening covering the top) within an experimental bin at 1200 hours on 20 May. While caged, each Anax was fed two 50-mg Rana sylvatica tadpoles. This was done to standardize hunger levels between Anax individuals and to ensure that Ambystoma larvae would be exposed to chemical cues indicating the presence of Anax before any predation could occur. Ambystoma larvae are capable of 
detecting cues produced by Anax feeding on Rana tadpoles (Yurewicz, unpublished data); tadpole prey were used because I did not have Ambystoma larvae available for this purpose.

Ambystoma larvae were introduced into the bins by 1400 hours on 20 May. I selected individuals from a very narrow size range for this experiment (mean mass of each species $\pm 1 \mathrm{SE}$ was $44 \pm 3 \mathrm{mg}$ ) so that the results would not be confounded by cannibalism or IGP among the salamanders (Yurewicz 2002). Larvae were allowed to acclimate overnight to the experimental conditions, and the following morning at 1030 hours I released the Anax from their cages. I counted the number of survivors of each species at approximately 8,23 , and 48 $\mathrm{h}$ after the Anax were released. During the same time period, I also ran four replicates of no-predator bins for each pairwise Ambystoma species combination.

For each pairwise combination of Ambystoma species, survival data were analyzed in a repeated-measures ANOVA that included the effects of species (A. tigrinum vs $A$. maculatum, A. tigrinum vs $A$. laterale, or $A$. laterale vs $A$. maculatum) and time (three observations). I used one-sample Kolmogorov-Smirnov tests and Levene's tests, respectively, to examine normality and homoscedasticity of the data and found no serious violations.

Natural pond survey

Between 1996 and 2000, I sampled 16 natural ponds in Livingston County, Mich. twice per year (once in late May to June, and once in mid- to late July). In nine of these ponds, I quantified densities of Ambystoma larvae and their potential invertebrate predators using a metal pipe that samples $0.1 \mathrm{~m}^{2}$ of surface area (1996-2000). The number of pipe samples taken per pond depended on pond size, ranging from 12 to 40 in the early sample and from 4 to 40 in the late sample (when some ponds had shrunk due to drying). I also sampled each of these ponds with a dipnet to search for rarer species. The other seven ponds were sampled only by dipnet for presence-absence data (1997-2000). During dipnet sampling, I slowly worked my way around the perimeter of a pond in a zig-zag pattern, sampling from different depths and microhabitats. Predatory invertebrate taxa identified in this survey were: larval Odonata (Aeshnidae, Libellulidae/Corduliidae), Coleoptera (larval and adult Dytiscidae and Hydrophilidae), Hemiptera (Belostomatidae, Nepidae, Notonectidae), larval Megaloptera (Corydalidae), and Decapoda (Cambaridae).

Sampled ponds fell into two discrete categories: closed- or opencanopy. Specifically, closed-canopy ponds were dark, closely surrounded by trees (with branches interdigitated above the pond), had few or no submerged or emergent macrophytes, and rarely (if ever) had duckweed (Lemna, Wolffia) (also see Werner and Glennemeier 1999). During the survey, I noted how many years each pond dried, and I used Mann-Whitney U tests to compare values between open- and closed-canopy ponds. Next, I calculated the reliability with which each Ambystoma species occupied each pond as the proportion of years sampled that the species was recorded. I then compared the mean reliability values for each species in closed- versus open-canopy ponds. In the same manner, I compared the reliability of occurrence of the major potential predator groups (larval odonates, crayfish, hemipterans, larval coleopterans, adult coleopterans, and larval megalopterans) and the total richness of invertebrate taxa (at the family level) between pond types. Mann-Whitney U tests were employed because survey data had heteroscedastic error variances that were not correctable by transformation.

Next, I compared the success of an intraguild prey species, $A$. maculatum, in different pond types. The success of A. laterale, which can also be an intraguild prey species, was not analyzed for two reasons: (1) its intraguild predator, A. tigrinum, was rarely encountered, and (2) its earlier hatching time makes it possible for this species to metamorphose before the time that the July survey was conducted (personal observation). For each pond-year in which A. maculatum was observed and the pond held water at least through the time of the July survey, I categorized the outcome as $A$. maculatum persistence (this species present in the July survey, $n=29$ ) or failure to persist (present in May or June but absent in July, $n=11$ ). For each pond, I calculated the proportion of years that $A$. maculatum persisted out of those years it was present, and I used a Mann-Whitney U test to compare these values between pond canopy types.

Data from ponds that were pipe-sampled were also used in MannWhitney $U$ tests to compare the May/June densities of each Ambystoma species and the sum of all predatory invertebrates by pond type. Finally, I explored the relationships between the May/ June densities of $A$. laterale, $A$. maculatum and predatory invertebrates in a series of linear regression analyses (A. tigrinum was not included in this set of analyses on account of its rarity). For the regressions, densities were log-transformed and only cases where the Ambystoma species of interest was present at detectable densities were analyzed.

\section{Results}

\section{Common garden experiment and predation trials}

Survival was high (pooled mean \pm 1 SE: $96.3 \pm 1.5 \%$ ) and was not affected by any of the treatments or their interactions (all $\mathrm{P} \geq 0.222$ ). Growth was higher in the block with 100-1 wading pools than with 75-1 pools $\left(F_{1,11}=13.2, P=0.004\right)$ and differed significantly between species $\left(F_{2,11}=26.6, P<0.001\right)$. A . tigrinum larvae grew significantly more than $A$. maculatum larvae $(P=0.0003)$ and tended to grow more than $A$. laterale larvae $(P=0.084)$. At the end of the experiment, $A$. tigrinum larvae weighed $489 \pm 34 \mathrm{mg}(\operatorname{mean} \pm 1 \mathrm{SE}), A$. laterale larvae weighed $374 \pm 22 \mathrm{mg}$, and $A$. maculatum larvae weighed $312 \pm 26 \mathrm{mg}$.

Behavior was influenced by a significant species-bypredator interaction $\left(F_{2,11}=67.9, P<0.001\right)$ and the blockby-predator interaction $\left(F_{1,11}=9.8, P=0.010\right)$. In no-predator pools, $A$. maculatum had the lowest activity $(P<0.001)$, while $A$. laterale and $A$. tigrinum had higher but similar activity levels $(P=0.372)$. All species reduced activity in response to the predator, but the degree of activity reduction differed such that in the pools with caged Anax, A. tigrinum was more active than $A$. laterale or A. maculatum $(P<0.001)$, and $A$. laterale was more active than $A$. maculatum $(P<0.001)$ (Fig. 2$)$. Activity in control pools was similar between blocks $(P=0.447)$ but, in caged Anax pools, activity was higher in the larger wading pools $(P=0.0004)$.

The three Ambystoma species also differed strongly in all measured aspects of morphology (Tables 1, 2). $A$. tigrinum larvae had longer and wider heads, deeper tail fins, narrower tail muscles, and shorter but wider and deeper bodies than larvae of the other two species $(P<0.001)$. Of all three species, $A$. laterale larvae had the longest bodies and shallowest tail muscles $(P<0.001)$; A. maculatum larvae had the narrowest heads, shortest but widest tail muscles, and the shallowest tail fins $(P<0.001)$. Ambystoma larvae also responded to the presence of caged predators with changes in tail and body characteristics (Table 1, Fig. 2). The lack of a significant species-bypredator interaction indicated that the three species shared similar morphological responses to Anax. Larvae raised 

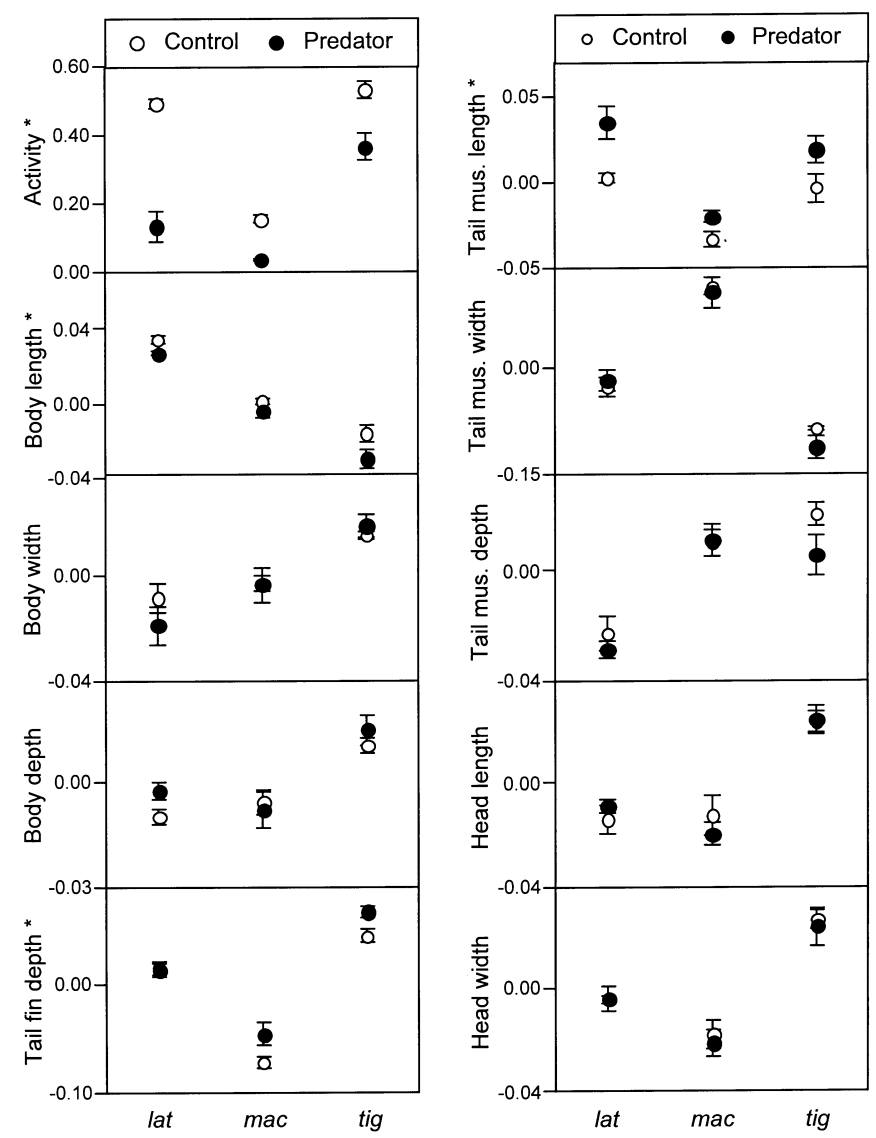

Fig. 2 Behavior and morphological characteristics (corrected for differences in body mass) of larvae of three Ambystoma species (lat $=A$. laterale, $m a c=A$. maculatum, tig $=A$. tigrinum $)$ in the presence and absence of caged Anax. Traits that differed by predator treatment are marked with asterisks. Data are means $\pm 1 \mathrm{SE}$

with Anax had shorter bodies, longer tail muscles, and deeper tail fins than larvae raised under control conditions.

In the laboratory predation trials, there were strong differences in vulnerability between Ambystoma species (Fig. 3). In bins with Anax, A. tigrinum larvae were killed more often than larvae of either $A$. laterale or $A$. maculatum $\left(F_{1,6} \geq 111.41, P<0.0001\right)$. A. laterale larvae were killed more often than $A$. maculatum larvae $\left(F_{1,6}=656.10, P<0.0001\right)$.

Table 1 Multivariate results from the MANOVA examining the effect of species (Ambystoma laterale, A. maculatum, A. tigrinum) and predator treatment (control, caged Anax) on nine morphological variables

\begin{tabular}{llll}
\hline Multivariate tests & & & \\
\hline Source & $d f$ & Wilks' $F$ & $P$ \\
\hline Species & 18,20 & 53.05 & $<0.001$ \\
Predator & 9,10 & 6.20 & 0.004 \\
Species $\times$ predator & 18,20 & 1.29 & 0.291 \\
\hline
\end{tabular}

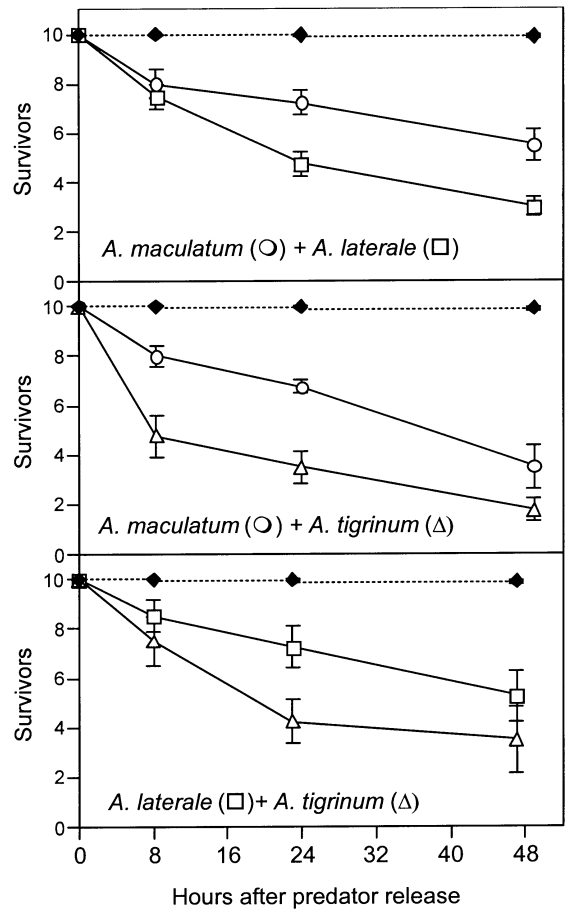

Fig. 3 Survival of Ambystoma species in pairwise laboratory predation trials with Anax. In each panel, mean survival in bins with no Anax is indicated by the dashed line with diamond symbols. Data are means $\pm 1 \mathrm{SE}$

Natural pond survey

Differences between open- versus closed-canopy ponds are summarized in Table 3. Briefly, closed-canopy ponds dried more frequently than open-canopy ponds. A. maculatum larvae were found more reliably and at higher May/June densities in open- than in closed-canopy ponds. In ponds where $A$. maculatum did occur, it was more likely to persist until late July in open-canopy ponds. Predatory invertebrate assemblages were more diverse at the family level but not denser in open-canopy ponds. Larval odonates, hemipterans, larval coleopterans and megalopterans all showed at least a tendency to be found more reliably in open-canopy than in closed-canopy ponds. In May/June, A. maculatum densities were positively related to predatory invertebrate densities $\left(F_{1,11}=11.81, P=0.006\right.$, $r^{2}=0.518$ ), while $A$. laterale densities tended to be negatively related to invertebrate densities $\left(F_{1,30}=3.33\right.$, $P=0.078, r^{2}=0.100$; Fig. 4).

\section{Discussion}

Traits that confer a competitive advantage often incur a cost in the form of heightened predation risk (Werner and Anholt 1993; Relyea 2002), and this ubiquitous trade-off creates a role for top predators in influencing the coexistence of competing prey species (e.g., Paine 1966). The results of this study indicate that, among Ambystoma larvae, traits of intraguild predators (particularly behavior) allow for rapid growth but render them 
Table 2 Univariate results from the MANOVA examining the effect of species (Ambystoma laterale, A. maculatum, A. tigrinum) and predator treatment (control, caged Anax) on nine morphological variables. Tests are only presented for effects that were significant at the multivariate level

Univariate tests $F$ statistic (upper value) and $P$ value (lower value)

\begin{tabular}{|c|c|c|c|c|c|c|c|c|c|c|}
\hline Source & $d f$ & Fin depth & Muscle length & Muscle width & Muscle depth & Body length & Body width & Body depth & Head length & Head width \\
\hline \multirow[t]{2}{*}{ Species } & 2,18 & 138.96 & 26.98 & 105.08 & 30.71 & 124.15 & 18.77 & 20.02 & 34.05 & 40.47 \\
\hline & & $<0.001$ & $<0.001$ & $<0.001$ & $<0.001$ & $<0.001$ & $<0.001$ & $<0.001$ & $<0.001$ & $<0.001$ \\
\hline \multirow[t]{2}{*}{ Predator } & 1,18 & 7.28 & 18.21 & 0.47 & 2.17 & 9.46 & 0.36 & 1.18 & 0.01 & 0.26 \\
\hline & & 0.015 & $<0.001$ & 0.500 & 0.158 & 0.007 & 0.556 & 0.291 & 0.915 & 0.616 \\
\hline
\end{tabular}

more vulnerable to a top predator (Anax) than intraguild prey. Thus, by differentially reducing the numbers and impact of intraguild predators, top predators may facilitate the persistence of intraguild prey. Survey data also provided some support for the idea that a trade-off between growth and mortality risk affects the distributions of Ambystoma intraguild predators and prey in natural ponds.

Top predators and coexistence between intraguild predators and prey

In the laboratory predation trials, intraguild predator species always suffered higher mortality from Anax than their intraguild prey species. The positive relationship between activity levels and vulnerability to the top predator was in agreement with studies on a variety of other taxa (Werner and Anholt 1993). Of course, predation risk may be affected by morphological traits as well as behavioral ones. Relatively little is known about the functional morphology of larval salamanders, but prior work on fish and larval anurans provides a basis for interpreting morphological differences among Ambystoma. In terms of traits that are likely to affect locomotion, larval salamanders share some characteristics with fish [elongate bodies and well-developed caudal skeletons, Hoff et al. (1989)] and some with tadpoles (e.g., large, fleshy tail fins). Members of all three groups adopt the same initial body position for fast starts involved in predator escape (Wassersug 1989). Since some of the key morphological traits that affect fast starts and turns are similar for tadpoles and fish (Webb 1984; Wassersug and Hoff 1985), it seems reasonable to assume that they play similar functional roles in larval salamanders.

Long, deep tail fins are often interpreted as effective anti-predator defenses for fish and tadpoles and have been shown to confer a survival advantage to tadpoles in the presence of lethal predators (Van Buskirk et al. 1997; Van Buskirk and Relyea 1998). Increases in the depth (Webb
Table 3 Summary of differences between open- and closed-canopy ponds in southeastern Michigan

\begin{tabular}{|c|c|c|c|}
\hline Variable & $\begin{array}{l}\text { Open-canopy } \\
{[\text { mean }(\mathrm{SE})]}\end{array}$ & $\begin{array}{l}\text { Closed-canopy } \\
{[\text { mean }(\mathrm{SE})]}\end{array}$ & $\begin{array}{l}P \text { value from } \\
\text { Mann-Whitney } U \text { test }\end{array}$ \\
\hline Proportion of years dried & $0.08(0.06)$ & $0.28(0.06)$ & 0.036 \\
\hline \multicolumn{4}{|l|}{ May/June densities per $\mathrm{m}^{2}$} \\
\hline A. laterale & $2.25(0.60)$ & $8.42(2.91)$ & 0.103 \\
\hline A. maculatum & $0.62(0.26)$ & $0.04(0.04)$ & 0.003 \\
\hline A. tigrinum & $0.02(0.02)$ & $0.02(0.02)$ & 0.898 \\
\hline Predatory invertebrates & $6.86(1.43)$ & $4.34(0.97)$ & 0.144 \\
\hline \multicolumn{4}{|l|}{ Reliability of pond occupancy } \\
\hline A. laterale & $0.79(0.09)$ & $0.68(0.08)$ & 0.335 \\
\hline A. maculatum & $0.73(0.11)$ & $0.36(0.10)$ & 0.012 \\
\hline A. tigrinum & $0.05(0.03)$ & $0.08(0.04)$ & 0.519 \\
\hline Larval odonates & $0.86(0.06)$ & $0.53(0.08)$ & 0.013 \\
\hline Larval coleopterans & $1.00(0.00)$ & $0.86(0.07)$ & 0.064 \\
\hline Adult coleopterans & $0.91(0.04)$ & $0.97(0.03)$ & 0.298 \\
\hline Hemipterans & $0.79(0.07)$ & $0.53(0.06)$ & 0.017 \\
\hline Megalopterans & $0.63(0.09)$ & $0.34(0.13)$ & 0.080 \\
\hline Crayfish & $0.18(0.12)$ & $0.16(0.10)$ & 0.702 \\
\hline Invertebrate family richness & $5.30(0.27)$ & $3.44(0.24)$ & $<0.001$ \\
\hline Persistence of $A$. maculatum & $0.86(0.05)$ & $0.42(0.16)$ & 0.029 \\
\hline
\end{tabular}



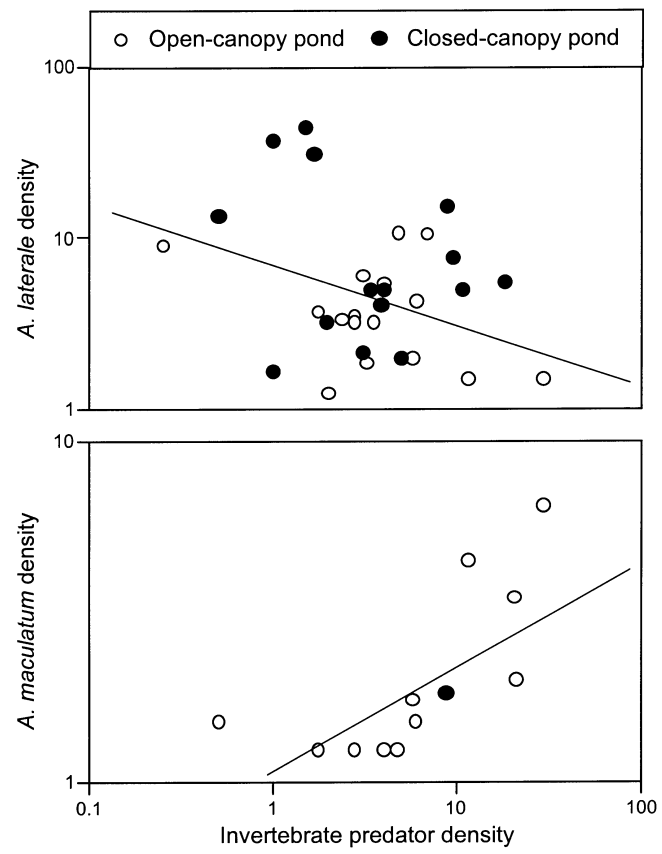

Fig. 4 The relationship between the densities (per $\mathrm{m}^{2}$ ) of predatory invertebrates and larval A. laterale (upper panel) or A. maculatum (lower panel) in a series of open- and closed-canopy ponds in southeastern Michigan. Lines are linear regressions fit through all log-transformed data points

1984; McCollum and Leimberger 1997) or the length (Huey 1980; Van Buskirk and McCollum 2000) of the tail fin can enhance swimming speed or maneuverability, which can be critical for escape once a predator is encountered (Watkins 1996). Tail length may also play a role in reducing turbulence, which can decrease detection risk by lowering the probability of stimulating a predator's mechanoreceptors (Wassersug and Hoff 1985). Further, tadpole tail fins are easily torn (Doherty et al. 1998), and increases in the relative size of the tail (length or depth) create a larger surface over which a predator strike may be non-lethal. Among the Ambystoma, if we interpret relatively long, deep tails as anti-predator defenses, $A$. tigrinum was the most morphologically defended salamander species, followed by $A$. laterale and then $A$. maculatum. This hierarchy was the same whether nonlethal predators were present or not, although each species did respond to the presence of caged Anax in an apparently adaptive direction by increasing relative tail fin depth and length (see Van Buskirk and Schmidt 2000).

In the predation trials, differences in relative tail length and depth between Ambystoma species were associated with differences in mortality, but not in the predicted direction: species that appeared to be more morphologically defended actually suffered higher mortality from Anax than species with shallower, shorter tails. These results are in contrast to those of Relyea (2001b), who found a negative relationship between tail fin depth and predation rates by Anax across different species of tadpoles. This suggests either that the relationships between morphological traits and swimming ability are very different for larval salamanders versus tadpoles, or that Ambystoma behavior is more important than morphology in determining predation risk from Anax. Detailed investigation of larval salamander locomotion and escape tactics from predators will be required to distinguish between these possibilities.

The differences in vulnerability between species in this study suggest that the top predator has the capacity to facilitate the persistence of intraguild prey through density-mediated effects (i.e., by preferentially removing intraguild predators, top predators may reduce their competitive and predatory impact on intraguild prey enough to permit coexistence). Two recent studies of invertebrates (Wissinger et al. 1999; Suhling 2001) have also demonstrated that intraguild predators are more active and experience higher top predator-imposed mortality than their intraguild prey. The potential for top predators to influence coexistence in many systems with IGP through density-mediated effects deserves further investigation in a variety of taxa to assess whether this may be a general pattern.

Since the species in this study were phenotypically plastic, the top predator could also influence coexistence within the guild via trait-mediated effects (i.e., by affecting the traits and thereby the performance of the intraguild predators and prey, the top predator could alter the dynamics of intraguild interactions). Because this requires the top predator to have differential effects on the traits of the intraguild predator and prey, this would have to operate via behavior as opposed to morphology for the Ambysto$m a$ studied here. Predator-induced behavioral plasticity has been shown to alter interspecific competition in simple food webs (Persson 1991; Werner and Anholt 1996; Kuhara et al. 1999). However, the potential behavioral responses of intraguild prey to their intraguild predators as well as the top predators add another layer of complexity to systems with IGP. Consequently, we need to understand how activity levels change when all species are raised together in order to predict whether top predators are likely to influence intraguild coexistence via trait-mediated effects. Building up from detailed data on the traits of each of the interacting species when raised separately and in combination should make this possible, at least within an experimental context (e.g., Relyea and Yurewicz 2002).

Growth rates and their implications for intraguild interactions

The results from the common garden experiment conformed to the general expectation of a positive relationship between activity and growth rates (Werner and Anholt 1993) in that the species with the consistently highest activity level (A. tigrinum) was also the fastest growing. However, two predictions based on this relationship were not met. First, $A$. laterale should have grown faster than $A$. maculatum but did not. Second, predator-induced decreases in activity should have reduced growth but did not. Two factors related to the experimental conditions may 
help explain these observations. First, the three Ambysto$m a$ species were not all raised in the pools at the same time and thus likely experienced different environmental conditions (e.g., temperature, day length). In particular, this complicates making comparisons between $\mathrm{A}$. maculatum and the other two species. Second, resources (zooplankton) were supplied ad libitum and probably were not always abundant enough to match the potential of the Ambystoma larvae to exploit them. Thus, within species, animals in no-predator pools may have depleted their resources quickly and then had to wait until the next food addition, while animals in pools with caged Anax may have had slower intake rates but could have depleted resources to the same overall level. Indeed, experimental work on larval amphibians suggests that induced responses to predation risk are more likely to limit growth when resources are abundant (Van Buskirk and Yurewicz 1998; Peacor and Werner 2000). Despite the limitations of the common garden experiment, previous work on Ambystoma suggests that the growth differences between these three species are likely to reflect the hierarchy in activity levels that I observed. Experimental work under more controlled conditions supports the conclusion that $A$. tigrinum is a faster-growing species than its congeners (Keen et al. 1984; Yurewicz 2002), and that the growth or developmental rates of $A$. laterale larvae often exceed those of A. maculatum (Talentino and Landre 1991; Yurewicz 2002).

Although the implications of specific morphological traits to foraging ability in larval salamanders have received relatively little attention, differences in relative head, body, and tail size between Ambystoma may also influence their growth. First, possession of a long body may provide a competitive advantage as appears to be the case for larval anurans (Relyea 2002), perhaps by providing an increased area for resource processing (Smith and Van Buskirk 1995). If this is true, then morphology as well as behavior can mediate the trade-off between predation risk and growth, since Anax-induction caused concomitant increases in tail fin depth and decreases in body length (Relyea 2002). Second, having a large head can enhance an individual's ability to hold and manipulate larger prey items (Reilly et al. 1992) which can lead to enhanced growth rates (Maret and Collins 1996). The benefits of large head size would probably be far greater in natural communities where insects and tadpoles are often available in addition to small zooplankton prey. And, finally, the same tail characteristics (e.g., increased length and depth) that aid in predator evasion could also provide an advantage in the rapid lunging movements that larval salamanders use to capture small prey in the water column (Hoff et al. 1985). Thus, the traits of A. tigrinum larvae (relatively large heads and deep tail fins) may equip them well for the utilization of larger prey items and rapid lunging at prey, whereas traits of $A$. laterale and $A$. maculatum larvae (relatively long bodies) may be better suited for resource processing. Clearly, further study of the functional morphology of larval salamanders is needed for a rigorous interpretation of the trait differences between species. However, these results serve as a reminder that morphological traits, like behavioral ones, can affect multiple aspects of performance. Investigating the functional value of these traits in different ecological contexts will improve our ability to predict or explain performance trade-offs within and between species.

Most empirical work on IGP has focused on survival differences between intraguild predators and prey, but differences in growth potential have important implications for competition and species coexistence and deserve more attention. Several previous studies have also shown that, among taxonomically similar species, intraguild predators have higher absolute growth rates than their intraguild prey when raised separately under the same conditions (Hurd 1988; Griffiths et al. 1994; Wissinger et al. 1996; Suhling 2001). Further, growth advantages for intraguild predators are likely to be established or exacerbated when guild members interact, since intraguild predators can both consume intraguild prey and cause them to modify their behavior or habitat use (Polis and Holt 1992). The faster growth rates and larger body sizes (Polis et al. 1989) of intraguild predators in my study system and others suggest that they will have higher intake needs (Peters 1983) and an advantage in interference competition (Persson 1985) compared to intraguild prey. If slow-growing intraguild prey have a competitive edge, it is more likely to be in the realm of tolerating lower resource levels and perhaps processing resources more efficiently than intraguild predators (Holt and Polis 1997). Relatively few studies have directly evaluated the relative competitive abilities of intraguild predators and prey, despite the important role that they play in theory in these systems. Approaching future experimental work on competitive dynamics between intraguild predators and prey from a mechanistic perspective should enhance our understanding of the criteria for their coexistence.

Intraguild predator and prey distributions across a habitat gradient

Given that activity levels appear to mediate a trade-off between growth potential and predation risk among Ambystoma, differences between the intraguild predator and prey species can be used to generate predictions about their distributions along habitat gradients (Wellborn et al. 1996). First, the ability to grow and develop rapidly may enable intraguild predators to exploit more ephemeral habitats than intraguild prey (Wissinger et al. 1999). Among the ponds I surveyed, closed-canopy ponds dried more frequently than open-canopy ponds, presenting a risk of catastrophic mortality to larval amphibian populations if metamorphosis is not achieved before the habitat disappears (Shoop 1974; Skelly 1995). Second, trait differences between intraguild predators and prey should influence their relative success in habitats with different top predator communities (Wissinger et al. 1999; Suhling 2001). Open-canopy ponds had richer predatory invertebrate assemblages (Lundqvist et al. 2001; Relyea 2002), 
and had at least a marginally non-significant tendency to more reliably host four of the six major invertebrate predator groups.

Based on these observations, open-canopy ponds should be better habitats for intraguild prey species than their intraguild predators. The low activity of $A$. maculatum (an intraguild prey species) should improve its success (relative to the other Ambystoma species) in environments with high predation risk by virtue of its low vulnerability, yet it should also decrease its relative success in very temporary habitats where growth must be rapid to reach metamorphosis before pond drying. This may help explain why A. maculatum occurred more regularly, was present at higher densities, and was more likely to persist through the summer in open-canopy ponds. Meanwhile, the two species that can act as intraguild predators, A. tigrinum and $A$. laterale, were distributed similarly between openand closed-canopy ponds. The observation that these species did not preferentially use closed-canopy ponds may reflect the fact that in southeastern Michigan these ponds sometimes fail to fill in time for adult breeding in the spring or dry too rapidly for any salamander species to complete development (personal observation). This may present at least as significant a risk of larval cohort failure as predation by invertebrates in open-canopy ponds.

Survey data on larval population densities also provided possible support for the idea of top predator-mediated coexistence between an intraguild predator species $(A$. laterale) and its intraguild prey (A. maculatum). Specifically, the densities of predatory invertebrates were positively related to densities of the intraguild prey species but inversely related to densities of the intraguild predator. This pattern is consistent with the idea that intraguild prey fare better when top predators are present to reduce the numbers and impact of intraguild predators. Of course, there are alternative explanations. For example, this pattern could be generated by oviposition choices of adult salamanders if $A$. maculatum avoided laying eggs in ponds with abundant $A$. laterale and few invertebrates. Since larval salamander and invertebrate populations fluctuate considerably across years (personal observation), adults would have to assess the abundance of congenerics and predatory invertebrates each year and possibly forego reproduction or travel to a different pond to lay eggs if their initial destinations were inappropriate. Given the philopatry and limited home ranges of A. maculatum (Husting 1965; Whitford and Vinegar 1966; Kleeberger and Werner 1983), this seems relatively improbable. Even so, the differential distribution of $A$. laterale and $A$. maculatum with respect to predatory invertebrates cannot be used on its own as evidence for top predator-mediated coexistence in this guild; other unmeasured attributes of the ponds could also have been correlated with differences in their densities. However, using experimental and natural survey data together will put us in the best position to identify not just possible mechanisms of coexistence for intraguild predators and prey but rather those that may have a demonstrably important effect on structuring natural communities.
To conclude, making connections between species' traits, performance, and distributions in nature presents significant challenges, including (but not limited to) working across different experimental or observational scales and confronting the complexity within natural communities. Despite such difficulties, this approach can be used to generate predictions relevant to a variety of species for a more complete understanding of community structure (Tilman 1982; Wellborn et al. 1996; Werner 1998). In this study, differences in behavioral and morphological traits between intraguild predators and prey provided insight into their growth and survival and suggested that top predators may be important in mediating coexistence between guild members (Wissinger et al. 1999). Further investigation is needed to determine if this is a common phenomenon in communities with IGP and, more broadly, whether placing intraguild predators and prey back into a broader community context in experiments and theory will help solve the puzzle of species coexistence with IGP.

Acknowledgements Many thanks to Neil Kubica, Brian Allan, Melissa Gonzalez, Koren Spence, and Earl Werner for help during the pond survey, to Melissa Gonzalez for assistance with the predation trials, and to Rick Relyea for advice on the common garden experiment. I am grateful to the Michigan DNR for permission to sample in the Pinckney State Recreation Area. Comments from David Allan, Deborah Goldberg, Shannon McCauley, Josh Van Buskirk, Earl Werner, and two anonymous reviewers improved this manuscript. This research was supported by grants from the University of Michigan's Department of Biology and Museum of Zoology as well as a Predoctoral Fellowship from the National Science Foundation. Animal care was within institutional guidelines.

\section{References}

Brophy TE (1980) Food habits of sympatric larval Ambystoma tigrinum and Notophthalmus viridescens. J Herpetol 14:1-6

Caldwell JP, Thorp JH, Jervey TO (1980) Predator-prey relationships among larval dragonflies, salamanders, and frogs. Oecologia 46:285-289

Diehl S (1993) Relative consumer sizes and the strengths of direct and indirect interactions in omnivorous feeding relationships. Oikos 68:151-157

Dixon WJ (1950) Analysis of extreme values. Ann Math Stat 21:488-506

Dixon WJ (1951) Ratios involving extreme values. Ann Math Stat 22:68-78

Doherty PA, Wassersug RJ, Lee JM (1998) Mechanical properties of the tadpole tail fin. J Exp Biol 201:2691-2699

Griffiths RA, de Wijer P, May RT (1994) Predation and competition within an assemblage of larval newts (Triturus). Ecography 17:176-181

Hoff KS, Lannoo MJ, Wassersug RJ (1985) Kinematics of midwater prey capture by Ambystoma (Caudata: Ambystomatidae) larvae. Copeia 1985:247-251

Hoff KS, Huq N, King VA, Wassersug RJ (1989) The kinematics of larval salamander swimming (Ambystomatidae: Caudata). Can J Zool 67:2756-2761

Holt RD, Polis GA (1997) A theoretical framework for intraguild predation. Am Nat 149:745-764

Huey RB (1980) Sprint velocity of tadpoles (Bufo boreas) through metamorphosis. Copeia 1980:537-540 
Hurd LE (1988) Consequences of divergent egg phenology to predation and coexistence in two sympatric, congeneric mantids (Orthoptera: Mantidae). Oecologia 76:549-552

Husting EL (1965) Survival and breeding structure in a population of Ambystoma maculatum. Copeia 1965:352-362

Keen WH, Travis J, Juilianna J (1984) Larval growth in three sympatric Ambystoma salamander species: species differences and the effects of temperature. Can J Zool 62:1043-1047

Kleeberger SR, Werner JK (1983) Postbreeding migration and summer movement of Ambystoma maculatum. J Herpetol $17: 176-177$

Kuhara N, Nakano S, Miyasaka H (1999) Interspecific competition between two stream insect grazers mediated by non-feeding predatory fish. Oikos 87:27-35

Lundqvist E, Landin J, Milberg P (2001) Diving beetle (Dytiscidae) assemblages along environmental gradients in an agricultural landscape in southeastern Sweden. Wetlands 21:48-58

Maret TJ, Collins JP (1996) Effect of prey vulnerability on population size structure of a gape-limited predator. Ecology 77:320-324

McCollum SA, Leimberger JD (1997) Predator-induced morphological changes in an amphibian: predation by dragonflies affects tadpole shape and color. Oecologia 109:615-621

Nyman S (1991) Ecological aspects of syntopic larvae of Ambystoma maculatum and the A. laterale-jeffersonianum complex in two New Jersey ponds. J Herpetol 25:505-509

Paine RT (1966) Food web complexity and species diversity. Am Nat 100:65-75

Peacor SD, Werner EE (2000) Predator effects on an assemblage of consumers through induced changes in consumer foraging behavior. Ecology 81:1998-2010

Persson L (1985) Asymmetrical competition: are larger animals competitively superior? Am Nat 126:261-266

Persson L (1991) Behavioral response to predators reverses the outcome of competition between prey species. Behav Ecol Sociobiol 28:101-105

Peters RH (1983) The ecological implications of body size. Cambridge University Press, Cambridge

Polis GA, Holt RD (1992) Intraguild predation: the dynamics of complex trophic interactions. Trends Ecol Evol 7:151-154

Polis GA, Myers CA, Holt RD (1989) The ecology and evolution of intraguild predation: potential competitors that eat each other. Annu Rev Ecol Syst 20:297-330

Power ME, Tilman D, Estes JA, Menge BA, Bond WJ, Mills LS, Daily G, Castilla JC, Lubchenco J, Paine RT (1996) Challenges in the quest for keystones. BioScience 46:609-620

Reilly SM, Lauder GV, Collins JP (1992) Performance consequences of a trophic polymorphism: feeding behavior in typical and cannibal phenotypes of Ambystoma tigrinum. Copeia 1992:672-679

Relyea RA (2001a) Morphological and behavioral plasticity of larval anurans in response to different predators. Ecology $82: 523-540$

Relyea RA (2001b) The relationship between predation risk and antipredator responses in larval anurans. Ecology 82:541-554

Relyea RA (2002) Competitor-induced plasticity in tadpoles: consequences, cues, and connections to predator-induced plasticity. Ecol Monogr 72:523-540

Relyea RA, Yurewicz KL (2002) Predicting community outcomes from pairwise interactions: integrating density- and traitmediated effects. Oecologia 131:569-579

Shoop CR (1974) Yearly variation in larval survival of Ambystoma maculatum. Ecology 55:440-444

Skelly DK (1995) A behavioral trade-off and its consequences for the distribution of Pseudacris treefrog larvae. Ecology 76:150 164

Skelly DK, Werner EE, Cortwright SA (1999) Long-term distributional dynamics of a Michigan amphibian assemblage. Ecology $80: 2326-2337$
Smith DC, Van Buskirk J (1995) Phenotypic design, plasticity, and ecological performance in two tadpole species. Am Nat 145:211-233

Suhling F (2001) Intraguild predation, activity patterns, growth and longitudinal distribution in running water odonate larvae. Arch Hydrobiol 151:1-15

Talentino KA, Landre E (1991) Comparative development of two species of sympatric Ambystoma salamanders. J Freshw Ecol $6: 395-401$

Tilman D (1982) Resource competition and community structure. Princeton University Press, Princeton, NJ

Van Buskirk J (1988) Interactive effects of dragonfly predation in experimental pond communities. Ecology 69:857-867

Van Buskirk J, McCollum SA (2000) Functional mechanisms of an inducible defense in tadpoles: morphology and behavior influence mortality risk from predation. J Evol Biol 13:336-347

Van Buskirk J, Relyea RA (1998) Selection for phenotypic plasticity in Rana sylvatica tadpoles. Biol J Linn Soc 65:301-328

Van Buskirk J, Schmidt BR (2000) Predator-induced phenotypic plasticity in larval newts: trade-offs, selection, and variation in nature. Ecology 81:3009-3028

Van Buskirk J, Yurewicz KL (1998) Effects of predators on prey growth rate: relative contributions of thinning and reduced activity. Oikos 82:20-28

Van Buskirk J, McCollum SA, Werner EE (1997) Natural selection for environmentally induced phenotypes in tadpoles. Evolution 51:1983-1992

Wassersug RJ (1989) Locomotion in amphibian larvae (or, "Why aren't tadpoles built like fishes?"). Am Zool 29:65-84

Wassersug RJ, Hoff KS (1985) The kinematics of swimming in anuran larvae. J Exp Biol 119:4-30

Watkins TB (1996) Predator-mediated selection on burst swimming performance in tadpoles of the Pacific tree frog, Pseudacris regilla. Physiol Zool 69:154-167

Webb PW (1984) Body form, locomotion and foraging in aquatic vertebrates. Am Zool 24:107-120

Wellborn GA, Skelly DK, Werner EE (1996) Mechanisms creating community structure across a freshwater habitat gradient. Annu Rev Ecol Syst 27:337-363

Werner EE (1998) Ecological experiments and a research program in community ecology. In: Resetarits WJ Jr, Bernardo J (eds) Experimental ecology: issues and perspectives. Oxford University Press, New York, pp3-26

Werner EE, Anholt BR (1993) Ecological consequences of the trade-off between growth and mortality rates mediated by foraging activity. Am Nat 142:242-272

Werner EE, Anholt BR (1996) Predator-induced behavioral indirect effects: consequences to competitive interactions in anuran larvae. Ecology 77:157-169

Werner EE, Glennemeier KS (1999) Influence of forest canopy cover on the breeding pond distributions of several amphibian species. Copeia 1999:1-12

Werner EE, Peacor SD (2003) A review of trait-mediated indirect interactions in ecological communities. Ecology 84:1083-1100

Whitford WG, Vinegar A (1966) Homing, survivorship, and overwintering of larvae in spotted salamanders, Ambystoma maculatum. Copeia 1966:515-519

Wilbur HM (1972) Competition, predation, and the structure of the Ambystoma-Rana sylvatica community. Ecology 53:3-21

Wissinger SA, Sparks GB, Rouse GL, Brown WS, Steltzer H (1996) Intraguild predation and cannibalism among larvae of detritivorous caddisflies in subalpine wetlands. Ecology 77:2421-2430

Wissinger SA, Whiteman HH, Sparks GB, Rouse GL, Brown WS (1999) Foraging trade-offs along a predator-permanence gradient in subalpine wetlands. Ecology 80:2102-2116

Yurewicz KL (2002) Size structure and intraguild interactions in larval salamanders. $\mathrm{PhD}$ dissertation, University of Michigan 